\title{
A METAMORFOSE DO ESTADO: A TRANSIÇÃO DA LÓGICA SOCIAL PARA A PENAL EM LOÏC WACQUANT
}

\author{
LA METAMORFOSIS DEL ESTADO: LA TRANSICIÓN DE LA LÓGICA SOCIAL A LA \\ PENAL EM LOÏC WACQUANT
}

\author{
THE METAMORPHOSIS OF THE STATE: THE TRANSITION FROM SOCIAL TO \\ PENAL LOGIC IN LOÏC WACQUANT
}

\author{
Paulo José de Carvalho MOURA ${ }^{1}$ \\ Mateus Tobias VIEIRA ${ }^{2}$
}

RESUMO: O presente artigo tem por objetivo discorrer sobre o declínio do EstadoProvidência e a emergência do Estado Penal a partir da revisão bibliográfica da tese desenvolvida por Loïc Wacquant (2001; 2003; 2008; 2015). Para tanto, primeiramente, apresentamos as inspirações teóricas na elaboração dessa tese central, que tem na sociologia relacional de Pierre Bourdieu sua origem; em seguida, contextualizamos o processo de metamorfose que teria ocorrido a partir de meados dos anos 1970 do século XX, marcado como uma 'grande transformação' nas estruturas do Estado-Providência (Welfare State), que vê sua lógica social ser substituída pela consolidação da lógica penal, caracterizada pela criminalização da pobreza e do encarceramento em massa.

PALAVRAS-CHAVE: Estado social. Estado penal. Campo burocrático. Loïc Wacquant. Pierre Bourdieu.

RESUMEN: El propósito de este artículo es discutir el declive del Estado de bienestar y el surgimiento del Estado penal a partir de la revisión bibliográfica de la tesis desarrollada por Loïc Wacquant (2001; 2003; 2008; 2015). Con este fin, en primer lugar, presentamos las inspiraciones teóricas en la elaboración de esta tesis central, que tiene su origen en la sociología relacional de Pierre Bourdieu; Luego, contextualizamos el proceso de metamorfosis que se habría ocurrido a partir de mediados de los años 70 del siglo XX, marcado como una 'gran transformación' en las estructuras del Estado de Bienestar (Welfare state), que ve sustituida su lógica social por la consolidación de la lógica penal, caracterizada por la criminalización de la pobreza y el encarcelamiento masivo.

PALABRAS CLAVE: Estado de bienestar. Estado penal. Campo burocrático. Loïc Wacquant. Pierre Bourdieu.

\footnotetext{
${ }^{1}$ Universidade Estadual Paulista (UNESP), Araraquara - SP - Brasil. Mestrando no Programa de Pós-Graduação em Ciências Sociais. Pesquisador no Núcleo de Estudos e Pesquisa sobre Sociedade, Poder, Organização e Mercado (NESPOM). Bolsista FAPESP (Processo n. 2019/24480-8). ORCID: https://orcid.org/0000-0003-31204105. E-mail: paulo.moura@unesp.br

${ }^{2}$ Universidade Estadual Paulista (UNESP), Araraquara - SP - Brasil. Mestrando no Programa de Pós-Graduação em Ciências Sociais da UNESP. Pesquisador no Núcleo de Estudos e Pesquisa sobre Sociedade, Poder, Organização e Mercado (NESPOM). Bolsista FAPESP (Processo n. 2019/08738-5). ORCID: https://orcid.org/0000-0002-6558-8779. E-mail: mateus.tobias@unesp.br
} 
ABSTRACT: This article aims to discuss the decline of the welfare State and the emergence of the penal state based on the bibliographic review of the thesis developed by Loïc Wacquant (2001; 2003; 2008; 2015). To do so, we first present the theoretical inspirations in the elaboration of this central thesis, which has Pierre Bourdieu's relational sociology as its origin; then we contextualize the process of metamorphosis that would have occurred from the mid-1970s onwards, marked as a 'great transformation' in the structures of the Welfare State, which sees its social logic being replaced by the consolidation of penal logic, characterized by the criminalization of poverty and mass incarceration.

KEYWORDS: Welfare state. Penal state. Bureaucratic field. Loïc Wacquant. Pierre Bourdieu.

\section{Introdução}

O presente artigo tem por objetivo discorrer sobre o declínio do Estado-Providência e a emergência do Estado Penal a partir da revisão bibliográfica da tese desenvolvida por Loïc Wacquant $(2001 ; 2003 ; 2008 ; 2015)$. Para tanto, primeiramente, apresentamos as inspirações teóricas na elaboração dessa tese central, que tem na sociologia relacional de Pierre Bourdieu sua origem; em seguida, contextualizamos o processo de metamorfose que teria ocorrido a partir de meados dos anos 70 do século $\mathrm{XX}$, marcado como uma 'grande transformação' nas estruturas do Estado-Providência (Welfare State), que vê sua lógica social ser substituída pela consolidação da lógica penal, caracterizada pela criminalização da pobreza e do encarceramento em massa.

O sociólogo francês tece sua tese a partir do argumento central da emergência de um novo regime que conduz à punição da pobreza após uma transformação dos valores societários devido ao avanço do espírito liberal. Nesse processo histórico, o EstadoProvidência, representado como o lado maternal, caritativo, assistencialista, tende a ser substituído por um Estado prisional, representado com o lado paternal, a face punitiva dessa instituição.

A análise realizada tem os Estados Unidos da América (EUA) como lócus empírico das investigações. O autor enfatiza as particularidades do Estado americano em relação aos europeus e aos latino-americanos: se por um lado, cada um desses locais apresentaram uma face relativamente distinta e variada do chamado 'Welfare State', com políticas sociais mais tímidas em uns do que em outros; por outro, a face penal do Estado teria se mostrado em todos eles. Nesse aspecto, podemos afirmar que os esforços intelectuais empreendidos lançam luzes sobre um fenômeno social de complexidade e relevância crescente ao passo em que assumiria traços de 'problema crônico' em escala mundial. 
Conforme podemos observar, no caso do Brasil, a taxa de aprisionamento ${ }^{3}$ no ano de 1999 era de 118, enquanto no ano de 2019 a taxa subiu para 359,4, de modo que ocupamos a terceira colocação entre os países com maior número de pessoas presas, com um contingente de 773 mil pessoas encarceradas (BRASIL, 2020).

A velocidade do desdobramento desse duplo movimento social na vida cotidiana a saber, o processo de disciplinarização das finanças do Estado e a expansão das forças políticas de encarceramento - se torna o lócus do projeto intelectual do autor. Em termos epistemológicos, Wacquant busca superar a dicotomia entre abordagens materialistas e simbólicas, com a finalidade de captar os elementos objetivos em cada contexto, e que contaram com uma dimensão simbólica particular em cada caso em que esse processo ocorreu.

Entretanto, antes de aprofundarmos a discussão acerca da tese desenvolvida por Wacquant, em relação à passagem do Estado Social para o Estado penal, se faz necessário compreender a noção de Estado a qual o autor recorre e que tem sua inspiração teórica no pensamento de Pierre Bourdieu.

\section{Posicionando a noção de Estado no campo: o pensamento de Pierre Bourdieu}

Pierre Bourdieu delineia seu conceito de Estado, de forma mais sistemática, a partir dos anos 1990 nos cursos que ministrou no Collège de France, onde o autor avança nas proposições de Max Weber ao postular o Estado como instância de monopolização não apenas do uso legítimo da violência física, mas também da violência simbólica (BOURDIEU, 2014) e o amalgamando sob a égide do conceito de campo burocrático.

Nessa concepção, o Estado engendra nos agentes sociais formas de pensamento, inclusive o pensamento sobre o próprio Estado (BOURDIEU, 2014), se consubstanciando, portanto, como uma forma de poder simbólico, pois é o espaço onde se produzem princípios de representação legítima do mundo. Bourdieu $(2001 ; 2014)$ concebe o Estado como um espaço fragmentado (portanto, não como um conjunto monolítico e coordenado, conforme a visão convencional), alvo de disputas de diversas forças sociais que buscam deter o monopólio do poder simbólico legítimo desse campo burocrático (WACQUANT, 2015).

A constituição desse espaço é o resultado de um processo de longo prazo de concentração das diferentes modalidades de capitais que operam em uma dada formação

${ }^{3}$ Número calculado pela razão entre o número total de pessoas privadas de liberdade e a quantidade populacional do país, onde a razão obtida é multiplicada por $100 \mathrm{mil}$. 
social, especialmente o "capital jurídico como a forma objetificada e codificada de capital simbólico, que capacita o Estado a monopolizar a definição oficial de identidades, a promulgação de padrões de condutas e a administração da justiça" (BOURDIEU 1994, p. 4-9 apud WACQUANT, 2015, p. 7).

Assim, o Estado é pensado como um 'metacampo' que se encontra atravessado por lutas internas entre duas forças chamadas pelo autor de 'mão esquerda' e 'mão direita' do Estado. Em linhas bastante gerais, do lado direito, teríamos a concentração da força física e simbólica; enquanto do lado esquerdo, os mecanismos de redistribuição (BOURDIEU, 1998). Tais forças opostas estariam em constante luta simbólica e material pela capacidade de impor legitimamente categorias de agir e pensar sobre o mundo social.

Conforme define, a mão esquerda representa o lado feminino, maternal, sendo materializada pelos ditos 'Ministérios dos desperdícios', responsáveis pelas "funções sociais educação pública, saúde, habitação, bem-estar social e legislação trabalhista - que oferecem proteção e amparo às categorias sociais desprovidas de capital econômico e cultural" (WACQUANT, 2015, p. 7). Do outro lado, a mão direita representa o lado masculino, paternal, sendo encarregada da tarefa de "reforçar a nova disciplina econômica via cortes no orçamento, incentivos fiscais e 'desregulamentação' econômica (ou regulamentação em favor das empresas)" (WACQUANT, 2015, p. 7).

Suas investigações, sobretudo as apontadas em "Punir os pobres" (2003), ampliam a concepção de 'mão direita' estabelecida por Bourdieu e realizam uma significativa contribuição suprindo uma lacuna importante ao inserir novos atores e instituições, a saber, a polícia, os tribunais e a prisão como elementos centrais da 'mão direita' do Estado, junto com os Ministérios das áreas econômicas e orçamentárias (WACQUANT, 2003; 2011; 2015).

Compreender essa filiação teórica e as origens do conceito de Estado, que o autor se vale, se faz fundamental para pensar o processo de grande transformação no final da década de 1970 nos Estados Unidos, que ocasionou uma profunda alteração cognitiva, cultural, política e social nas relações estabelecidas pela presença do Estado na economia e na vida cotidiana. Entender esse jogo entre mão direita e mão esquerda possibilita compreender o papel do Estado na garantia do bem-estar e do pleno emprego e como essa função foi contraída ao máximo em favor da expansão descontrolada do regime prisional (prisonfare), do subemprego inescapável (workfare) e dos auxílios condicionais e formações obrigatórias e de baixas perspectivas (learnfare), elementos que resultam na prevalência do que se denomina Estado penal. 


\section{A 'grande transformação': o declínio do Estado-Providência e a emergência do Estado Penal}

Os Estados Unidos do pós-guerra, no final dos anos 1940, conheceu um período chamado por muitos de 'anos dourados', marcados pela regulação dos mercados financeiros, estabilidade financeira e de carreiras, elevadas taxas de crescimento econômico aliadas à manutenção do pleno de emprego, e redução das desigualdades (BRESSER-PEREIRA, 2010). Wacquant alerta que os Estados Unidos possui particularidades em relação a esse momento que ficou conhecido na Europa como 'Estado-Providência'4, uma vez que as políticas sociais americanas foram bastante tímidas em relação aos Estados europeus, o que leva-o a denominar o Estado americano de 'Estado-caritativo' onde, em outras palavras, o princípio da ação pública "não é a solidariedade, mas a compaixão; seu objetivo não é fortalecer laços sociais (e ainda menos reduzir as desigualdades), mas no máximo aliviar a miséria mais gritante" (WACQUANT, 2003, p. 20).

Vale explicitar que esse contexto é apreendido como um período histórico no qual os valores democráticos pautados nas premissas de igualdade, justiça social, redistribuição de bens e direitos redesenham a configuração da política moderna (WACQUANT, 2015) onde a existência de uma rede de proteção se coloca como dever do Estado e direito dos indivíduos enquanto cidadãos (MARSHALL, 1950). Nessa ordem, o trabalho constitui-se na fonte de segurança e fiadora da proteção social (a ideia de garantia do pleno emprego se encontra enraizada no rol de funções do Estado, assim como objetivo-fim da ação econômica).

Esse movimento deriva de uma série de conquistas e avanços iniciados a partir do século XVIII, quando a conquista do direito de igualdade política perante o Estado ocasionou uma grande transformação nos valores morais da sociedade ocidental. Assim, a partir do século XX, ocorreria a legitimação da crença de que não bastava somente que o Estado assegurasse os direitos à vida, à liberdade, à propriedade e à igualdade perante a lei, mas deveria garantir também meios de proteção (caracterizada pela intervenção estatal nos setores econômicos, sociais e culturais visando a garantia do pleno emprego, lazer, educação e serviços públicos) para um novo e pujante segmento: a classe trabalhadora.

Alguns historiadores pontuam ainda o papel da oposição entre democracias liberais e Estados socialistas, baseados na oposição entre União das Repúblicas Socialistas Soviéticas (URSS) e EUA.

${ }^{4}$ Conhecido também como Estado de Bem-Estar Social, Estado-Previdência etc. 
Uma das ironias deste estranho século é que o resultado mais duradouro da Revolução de Outubro, cujo objetivo era a derrubada global do capitalismo, foi salvar seu antagonista, tanto na guerra quanto na paz, fornecendo-lhe o incentivo - o medo - para reformar-se após a Segunda Guerra Mundial e, ao estabelecer a popularidade do planejamento econômico, oferecendo-lhe alguns procedimentos para sua reforma (HOBSBAWN, 1995, p. 292).

A partir de meados da década de 1970 e início da década de 1980, com o avanço do processo de financeirização das forças produtivas, de deslocamento do capital e da força de trabalho, que estimularam a mobilidade social e a intensificação dos fluxos migratórios, houve uma transformação que impactou diretamente na ordem socioeconômica moderna. Esse processo ocorreu através da mudança radical dos valores morais, especificamente, por meio da supremacia da ideia de que o livre mercado geraria condições ilimitadas de competição ao desenvolvimento e à expansão do bem-estar social, colocando em xeque os valores e toda a ordem social dos ditos 'anos dourados'.

Um duplo movimento ocorreu nessa ruptura com a lógica social, até então dominante no campo burocrático, e é nesse ponto que Wacquant salienta a necessidade de superação da "costumeira oposição entre as abordagens materialista e simbólica, derivadas das figuras emblemáticas de Karl Marx e Émile Durkheim” (WACQUANT, 2015, p. 6), já que esse processo se deu por uma mudança em elementos objetivos, marcadamente a diminuição do orçamento destinado à assistência social enquanto os gastos com o aparato penal subiam substancialmente, bem como uma mudança nos discursos, tendente a realocar a responsabilidade pela pobreza, dos desarranjos sociais, para desvios morais dos próprios afetados por ela.

Nesse contexto, diversos atores políticos assumiram importantes posições de governança como defensores (e produtos) desse movimento histórico, como arautos dessa visão disciplinadora. Como exemplos de maior relevância, podemos citar a eleição da primeira-ministra Margaret Thatcher, do Partido Conservador, no Reino Unido em 1979, e do republicano Ronald Reagan como presidente nos EUA em 1980.

Thatcher deu impulso ao credo liberal que tinha como projeto reduzir o papel do Estado na sociedade britânica. A primeira-ministra reduziu benefícios e apertou os gastos dos serviços públicos. Em gesto simbólico, a primeira linha de seu primeiro relatório oficial sobre gastos públicos declarava: “A despesa pública está no cerne das atuais dificuldades econômicas da Grã-Bretanha” (THE GUARDIAN, 2013, tradução nossa) ${ }^{5}$. Desde então, o

${ }^{5}$ Para maiores informações. THE GUARDIAN. Margaret Thatcher's policies hit the poor hardest - and it's happening again, 2013. Disponível em: https://www.theguardian.com/society/2013/apr/09/margaret-thatcherpolicies-poor-society. Acesso em: 23 jun. 2017. 
questionamento colocado sobre o tamanho do Estado estaria expresso pela máxima utilizada pelas autoridades no mundo todo sob a pretensa 'necessidade de cortar na carne' do EstadoNação, alegando ser este 'obeso, improdutivo, ineficiente e corrupto'.

A dimensão moral dessa 'nova' visão de mundo (que viria a ser dominante e transformar toda a ordem de relações sociais) aparece também em frases célebres como a dita por Reagan em 1968, durante a nomeação de Richard Nixon como candidato à presidência pelo Partido Republicano: "Devemos rejeitar a ideia de que cada vez que a lei é quebrada a culpada é a sociedade, e não o transgressor da lei. É hora de restaurar o preceito de que cada indivíduo é responsável por seus atos" (REAGAN, 1968, online, tradução nossa) ${ }^{6}$, ou ainda a frase de Margaret Thatcher, quase 20 anos depois, dada como resposta em entrevista concedida à revista feminina Woman's Own em Downing Street (sede do governo britânico), em 1987, em que a primeira-ministra assevera: "Mas o que é a sociedade? Não existe tal coisa. O que existe são homens e mulheres, indivíduos e famílias" (THATCHER, 2013, online $)^{7}$.

A consolidação de tais crenças no plano das políticas macroeconômicas se deu através do chamado "Consenso de Washington', alterando o escopo anteriormente focado no investimento em políticas de bem-estar social em favor de políticas de penalização da pobreza. Segundo Lebaron (2012), o Consenso de Washington foi a "ascensão incontestável das 'soluções de mercado', que vão de políticas orçamentárias e monetárias 'ortodoxas' à privatização massiva dos serviços públicos e à integração no mercado mundial dos capitais" (LEBARON, 2012, p. 54).

Desta feita, seguiu-se então uma onda de reformas e alterações institucionais que passaram a condicionar o acesso à assistência social à adoção de certas normas de conduta: "seja a obrigação de aceitar qualquer emprego (workfare), seja a que modula a assistência às famílias em função da assiduidade escolar de seus filhos (learnfare) ou da inscrição em pseudo-estágios de formação sem perspectivas” (WACQUANT, 2015, p. 10). A naturalização

\footnotetext{
${ }^{6}$ Para maiores informações: REAGAN, R. Ronald Reagan and Personal Responsibility. Reagan Group. 08, maio, 2017. Disponível em: https://bit.ly/2V3NDGf. Acesso em: 23. jun. 2020. A frase foi proferida por Reagan durante a Convenção Republicana em 31 de julho de 1968 em Miami, momento em que Richard M. Nixon foi nomeado como candidato oficial do Partido contra o Democrata Hubert Humphrey Disponível em: http://voices.washingtonpost.com/fact-checker/2011/01/palins use of blood libel and.html. Acesso em: 23. jun. 2020.

7 Para maiores informações: THATCHER, M. 'Essa coisa de sociedade não existe'. ESTADÃO, 2013. Disponível em: http://opiniao.estadao.com.br/noticias/geral,essa-coisa-de-sociedade-nao-existe- imp-,1019492. Acesso em: 23. jun. 2020.

${ }^{8}$ Um conjunto de propostas de políticas de liberalização dos mercados e reformas institucionais formulado por economistas de instituições financeiras situadas em Washington - como, o Fundo Monetário Internacional (FMI) e o Banco Mundial — no ano de 1989.
} 
de postulados liberais tais como governança corporativa, necessidade de contenção das demandas sociais, estímulo da competitividade, concorrência, eficiência e, principalmente, na ideia de austeridade fiscal (representada pela crença de que o Estado não pode gastar mais do que arrecada), tornaram-se uma doxa ${ }^{9}$ econômica.

É importante enfatizar que a guinada em direção ao Estado penal, policialesco e encarcerador, traz consigo uma incongruência fundamental: se por um lado o discurso de ascetismo fiscal é empregado com ferocidade em relação às políticas assistenciais, por outro, os gastos com o sistema penal disparam. Nesse aspecto, Batista (2003) aponta que Wacquant evidência a ausência de uma racionalidade objetiva no discurso de enxugamento de custos públicos ao observar atentamente a "voracidade orçamentária do Estado penal" (BATISTA, 2003, p. 11).

Desse modo, se efetiva a substituição de um Estado social e assistencialista (maternalista) por um Estado penal e punitivo (paternalista), em que o deslocamento da atividade estatal do braço esquerdo (social) para o braço direito (penal) fazem parte da 'remasculinização do Estado', conforme destaca o autor:

Longe de contradizer o projeto neoliberal de desregulamentação e falência do setor público, a irresistível ascensão do Estado penal americano é como se fora o negativo disso no sentido de avesso mas também de revelador -, na medida em que traduz a implementação de uma política de criminalização da miséria que é complemento indispensável da impossibilidade do trabalho assalariado precário e sub-remunerado como a negação cívica, assim como o desdobramento dos programas sociais num sentido restritivo e punitivo que lhe é concomitante (WACQUANT, 2011, p. 62-63).

Assim, o que se pode aferir é a convergência de dois fenômenos reciprocamente explicáveis e dependentes, no caso, a dissolução do Estado Social excluindo verdadeiras multidões das garantias então observadas por um Estado matriarcal e, como consequência dessa exclusão, o superpovoamento da malha jurídico-criminal e carcerária do novo Estado Penal.

\section{O reforço da 'mão direita' do Estado: uma nova ordem social baseada no Workfare $e$ Prisonfare}

O desmonte das estruturas do Estado-Providência, com a consequente redução de sua atuação na economia em temas como a garantia de acesso ao pleno emprego (ou seja, trabalho

${ }^{99}$ A doxa é "um ponto de vista particular, o ponto de vista dos dominantes, que se apresenta e se impõe como ponto de vista universal; o ponto de vista daqueles que dominam dominando o Estado e constituíram seu ponto de vista em ponto de vista universal ao criarem o Estado" (BOURDIEU, 1996, p. 120). 
de tempo integral, por período indeterminado e com salário adequado), a assistência social, a habitação e ao lazer, é acompanhado de uma alteração cognitiva e moral. Se anteriormente o acesso ao aparato social do Estado era visto como um "direito inquestionável" (WACQUANT, 2015, p. 5), após a transição para a nova ordem, o acesso a tais direitos passa a ter um caráter condicional em seus aspectos objetivos, e imoral em seu aspecto simbólico, sendo percebido como uma espécie de "dependência patológica" dos pobres em relação ao Estado (WACQUANT, 2003, p. 9).

Essa transição material e simbólica elege como principais culpados dos problemas sociais, a delinquência juvenil, os bairros sensíveis, os crimes de menor monta e, como sua solução óbvia e necessária, postula a penalização de todo aquele que seja pego na larga teia dos desviantes (WACQUANT, 2011), como já dito, o Estado não necessariamente torna-se menor quando globalmente considerado, mas remodela sua área de atuação prioritária, de modo que são redefinidas as "missões do Estado, que, em toda parte, se retira da arena econômica e afirma a necessidade de reduzir seu papel social e de ampliar, endurecendo-a, sua intervenção penal" (WACQUANT, 2011, p. 10).

Nessa lógica, o cidadão trabalhador e diligente, que busca pelo suor de suas mãos a colocação social e a conquista econômica se vê pilhado nas suas possibilidades, seja pelo perigo da violência urbana levada a cabo pelos criminosos, seja pelo pagamento de pesados impostos que atrasam a ascensão do contribuinte em favor do lasso e do desviante.

Nos Estados Unidos, um termo foi cunhado para designar o conjunto dessas pessoas: 'underclass'. Não se trata propriamente de uma classe social nos termos marxistas, tampouco de genérica designação para pobres e desvalidos, mas designa antes os 'maus pobres' de bairros segregados, responsáveis pelo próprio destino pauperizado e catalizadores da crise social (WACQUANT, 2001), conforme descreve:

Podemos reagrupar sumariamente os diversos usos da 'underclass' em três grandes famílias, segundo eles que destaquem a estrutura do mercado de trabalho, a conduta e os traços pessoais dos indivíduos incriminados ou as características sociais do bairro e do seu hábitat (WACQUANT, 2001, p. 95).

Essa 'underclass', responsável pela própria penúria, cliente diuturna das políticas sociais, deve ser estimulada ao trabalho (precário e sub-remunerado), já que a oferta de ajuda social torna o trabalho duro 'opcional'. Em caso de insubordinação, o braço direito do Estado os tomará para si em suas crescentes e permanentemente superlotadas prisões. 
[...] o sistema penal contribui diretamente para regular os segmentos inferiores do mercado de trabalho - e isso de maneira infinitamente mais coercitiva do que todas as restrições sociais e regulamentos administrativos. Seu efeito aqui é duplo. Por um lado, ele comprime artificialmente o nível do desemprego ao subtrair à força milhões de homens da "população em busca de um emprego" e, secundariamente, ao produzir um aumento do emprego no setor de bens e serviços carcerários, setor fortemente caracterizado por postos de trabalho precários (e que continua se elevando mais ainda com a privatização da punição) [...] (WACQUANT, 2011, p. 63).

Percebe-se que o perfil sociológico dos indivíduos que acessam as políticas sociais é o mesmo dos que são alcançados pelos tentáculos penais, o que permite objetivar um fenômeno peculiar, no caso, a prisão como substituta do gueto (WACQUANT, 2003). Essa substituição se dará institucionalmente pela aplicação da chamada política de 'Tolerância Zero', que possui como mote o combate duro e frontal à pequena criminalidade, supostamente responsável e estimuladora de crimes mais graves. Assim, nessa nova configuração, teríamos o gueto como prisão social e a prisão como gueto judiciário, realizando uma homologia entre duas organizações que possuem uma função histórica estratégica (BATISTA, 2003).

A prisão torna-se a instituição especial capaz de confinar os membros mais problemáticos das ditas 'multidões perigosas'. É por isto que, para Wacquant, o gueto "viu-se ligado ao sistema carcerário por uma tripla relação e equivalência funcional, de homologia estrutural e de sincretismo cultural, transformando-se gueto e prisão numa espécie de continuum como destino da população negra e jovem” (BATISTA, 2003, p. 13).

O que se verifica, portanto, é a consolidação de uma 'vigilância permanente dos espaços públicos' que se torna imprescindível para a nova ordem urbana, onde ocorre o "controle sistemático dos deslocamentos da juventude pobre" (BATISTA, 2003, p. 13). As investigações realizadas demonstram que a polícia, os tribunais e a prisão não constituem simples "apêndices técnicos, destinados ao cumprimento da ordem legal (como a criminologia afirmaria), mas sim veículos para a produção política da realidade e para a vigilância das categorias sociais desfavorecidas e difamadas e dos territórios que lhes são reservados" (WACQUANT, 2015, p. 17).

Inspirado em Bourdieu, Wacquant (2003) afirma que nos Estados Unidos se assiste em um desdobramento de um 'Estado-Centauro', entendido como sendo, “de um lado, um Estado que mantém as garantias sociais, mas para os privilegiados, suficientemente cacifados para que possam dar segurança, garantias; de outro, um Estado repressor, policialesco, para o povo" (BOURDIEU, 1998, p. 29). Os negros, população particularmente atingida por esse fenômeno, se veem confinados no que concerne ao espaço social restrito e sempre alvos 
preferenciais do aparato penal do Estado, em situação descrita por Bourdieu como "uma espécie de realização dos sonhos dos dominantes" (BOURDIEU, 1998, p. 30), conforme pontua em outra passagem:

\begin{abstract}
Os negros do gueto de Chicago só conhecem, do Estado, o policial, o juiz, o carcereiro e o parole officer, isto é o oficial que aplica as penas, diante de quem eles devem se apresentar regularmente, sob risco de voltar à prisão [...] Um Estado que, como mostrou Loïc Wacquant, se reduz cada vez mais à sua função policial (BOURDIEU, 1998, p. 29).
\end{abstract}

Ao cabo dessa transição, as manifestações efetuadas por grupos sociais marginalizados passaram a ser compreendidas pelo Estado Penal como “intoleráveis e destruidoras da governabilidade" (WACQUANT, 2015). Por fim, a alteração intrínseca realizada na dinâmica do campo burocrático estabelece nos atos de Estado uma "contração contínua do bem-estar e pela expansão descontrolada do regime prisional” (WACQUANT, 2015, p. 9).

\title{
Considerações finais
}

O ineditismo da obra de Loïc Wacquant, no que concerne ao escopo desse artigo, consiste em mobilizar conceitos centrais da obra de Bourdieu, em particular a noção de campo burocrático e operacionalizar a ideia de 'mão esquerda' e 'mão direita' para demonstrar a passagem do chamado Estado-Providência na Europa e, sobretudo, do Estado-caritativo nos Estados Unidos, para o Estado penal (salientando que os Estados europeus não completaram essa transição, de modo que, se por um lado a face social outrora foi mais forte é patente que a face penal é mais branda).

Nota-se que, a partir da intensificação do corte dos recursos para as áreas sociais em nome da austeridade fiscal e da ampliação das políticas de vigilância e criminalização da pobreza, temos como resultado de uma queda de braço operada no interior do campo burocrático e a derrocada da 'mão esquerda do Estado' (representação da lógica do dom e da distribuição) em favor da 'mão direita' (representação da força e da disciplinarização) na disputa pelo monopólio legítimo da violência material e simbólica e, em última instância, da capacidade de produção da realidade social.

Ao seguir Bourdieu de forma engajada na construção de seu objeto e na concretização de uma ruptura da contraditória dicotomia entre as abordagens materialista e simbólica, Wacquant contribui para pensarmos a grande transformação, tratada no presente artigo, como um duplo movimento enraizado no tecido social e seu contexto histórico. 
A transição entre essas duas formatações de Estado não se deu desacompanhada de um discurso que lhes desse fundamento, mais que isso, sem uma percepção de mundo, enfim, sem uma reviravolta simbólica no modo de compreender a pobreza, o gueto, a necessidade, a rebeldia, as manifestações e as revoltas. Ao traçar a origem das ideias neoliberais que fundamentaram o hiperindividualismo justificador de uma moralidade que prevê a atrofiamento do Estado social e o fortalecimento do Estado Penal, o autor nos mostra que discurso é ação, é condição de possibilidade, sem o qual toda transição seria não só incompreensível, mas impensável.

Por fim, o que se consolida, então, é a criação de uma nova doxa punitiva que se coloca enquanto outra face da denúncia do contrato social fordista-keynesiano, aplicando na sociedade os princípios liberais da economia de mercado através de forte desregulamentação social e econômica (supostamente indispensável para a sobrevivência da economia). Nessa lógica, discursos de inevitabilidade das decisões econômicas, de contingência do gasto público, no mais das vezes desacompanhadas de uma elucidação acerca de outros gastos (como é o caso do próprio sistema penal), são reforçadas pela crença na desnecessidade da manutenção de um Estado-providência, posto que indutor da degeneração moral ao privilegiar a inatividade, a preguiça.

Em que pese o contexto empírico dos estudos de Wacquant levarem em consideração especialmente os Estados Unidos, muito dessa passagem pode ser aproveitada para leituras da realidade latino-americana, em particular o Brasil. Se por um lado não conhecemos, como na Europa, o Estado-providência, dado que o país oscila entre momentos de maior e menor engajamento com o Estado-caritativo, por outro, sob o aspecto penal, recortes populacionais como alvos preferenciais da política penal, caracterizados por segmentações geográficas, sociais e de pertencimento étnico são uma realidade aferível por estatísticas longevas e a ascensão de discursos penalmente dóxicos encontram nesse fim dos anos 10 e início dos anos 20 do século XXI um dos seus momentos mais frutíferos.

AGRADECIMENTOS: Gostaríamos de agradecer à Fundação de Amparo à Pesquisa do Estado de São Paulo (FAPESP) por todo suporte concedido. 


\section{REFERÊNCIAS}

BARSIL. Departamento Penitenciário Nacional. Levantamento Nacional de Informações Penitenciárias. Disponível em: https://www.gov.br/depen/pt-br/sisdepen. Acesso em: 02 de novembro de 2020.

BATISTA, V. M. Prefácio. In: WACQUANT, L. Punir os pobres: a nova gestão da miséria nos Estados Unidos. Rio de Janeiro, Editora Revan, 2003. p. 7-18.

BOURDIEU, P. Rethinking the state: on the genesis and structure of the bureaucratic field. Sociological Theory, v. 12, n. 1, p. 1-19, 1994

BOURDIEU, P. Razões práticas: sobre a teoria da ação. Campinas: Ed. Papirus, 1996.

BOURDIEU, P. Contrafogos 1. São Paulo: Jorge Zahar, 1998.

BOURDIEU, P. Contrafogos 2. São Paulo: Jorge Zahar, 2001.

BOURDIEU, P. Sobre o Estado. São Paulo: Companhia das Letras, 2014.

BRESSER-PEREIRA, L. C. A crise financeira global e depois: um novo capitalismo? Novos Estudos - CEBRAP, São Paulo, n. 86, p. 51-72, 2010.

HOBSBAWM, E. Era dos extremos: o breve século XX - 1914-1991. São Paulo:

Companhia das Letras, 1995.

LEBARON, F. A formação dos economistas e a ordem simbólica mercantil. REDD - Revista Espaço de Diálogo e Desconexão, Araraquara, v. 4, n. 2, p. 1-35, jan./jul. 2012.

MARSHALL, T. H. Citizenship and social class and other essays. Cambridge, UK: Cambridge University Press, 1950.

WACQUANT, L. As duas faces do gueto. São Paulo: Boitempo, 2008.

WACQUANT, L. As prisões da miséria. Trad. André Telles. Rio de Janeiro: Jorge Zahar Editor, 2011.

WACQUANT, L. Bourdieu, Foucault e o Estado Penal na Era Neoliberal. Revista Transgressões: ciências criminais em debate. v. 3, n. 1, p.5-22, 2015.

WACQUANT, L. Os condenados da cidade: um estudo sobre a marginalidade avançada. Rio Janeiro: Revan; Fase, 2001.

WACQUANT, L. Punir os pobres: a nova gestão da miséria nos Estados Unidos. 2. ed. Rio de Janeiro: Revan, 2003. 


\section{Como referenciar este artigo}

MOURA, P. J. C.; VIEIRA, M. T. A metamorfose do estado: a transição da lógica social para a penal em Loïc Wacquant. Rev. Sem Aspas, Araraquara, v. 9, n. 2, p. 247-260, jul./dez. 2020. e-ISSN: 2358-4238. DOI: https://doi.org/10.29373/sas.v9i2.14500

Submetido em: 26/11/2020

Revisões requeridas: $10 / 12 / 2020$

Aceito em: 10/02/2021

Publicado em: 01/03/2021 